\title{
PROJETO DE DESIGN DE EMBALAGENS BASEADO NA INTEGRAÇÃO INTERDISCIPLINAR
}

Giacomini Silva, Jucelia S; Doutora; Instituto Federal de Santa Catarina jucelia.giacomini@ifsc.edu.br

Ibarra, Caroline G.; Graduanda; Instituto Federal de Santa Catarina caroline.ibarra@gmail.com

Morgerot, Cleide L.; Graduanda; Instituto Federal de Santa Catarina cleidemorg@gmail.com

Rosa, Tayana P.; Graduanda; Instituto Federal de Santa Catarina tayanapr@gmail.com

Santos, Camila dos; Designer; Instituto Federal de Santa Catarina camilacamomila13@gmail.com

Resumo: $O$ presente artigo tem como objetivo apresentar os processos metodológicos realizados no módulo de Design de Embalagens do Curso de Tecnologia em Design de Produto do Instituto Federal de Santa Catarina. A proposta pedagógica do curso se fundamenta em uma perspectiva integradora e interdisciplinar, visando ampliar a vivência e a percepção dos discentes a partir da aproximação entre o conhecimento teórico e prático. O projeto foi realizado em parceria com a cooperativa "Grupo Associada" e buscou contribuir com a potencialização da competitividade e valorização dos produtos orgânicos, visando minimizar as dificuldades de inserção em novos nichos de mercado, que vêm sendo enfrentadas pelos pequenos grupos produtivos. $O$ processo de desenvolvimento do projeto fundamentou-se na aproximação entre os discentes e o contexto social, econômico e produtivo da cooperativa em questão, propiciando a aplicação dos conhecimentos e proposições de melhorias nas diversas fases do sistema-produto.

Palavras-chave: Design, Embalagem, Cooperativas, Interdisciplinaridade, Projeto Integrador. 


\begin{abstract}
This article aims to present the methodological processes performed in Packaging Design module in Course of Technology in Product Design at the Instituto Federal de Santa Catarina. The pedagogical purpose of this project is based on integrative and interdisciplinary perspective, aiming to expand the students' experience and perception trough relationship between theoretical and practical knowledge. The project was conducted in partnership with the cooperative "Grupo Associada" to improve competitiveness and organic products valorization in order to minimize the difficulties entering a new market which are being faced by small productive groups. The project development process was based on the closeness between students and the social, economic and productive features of the cooperative. This approach allowed the knowledge application and propositions for improvements in the different product system phases.
\end{abstract}

Key-words: Design, Packaging, Cooperatives, Interdisciplinarity, Integrated Project.

\title{
1. INTRODUÇÃO
}

O projeto apresentado ao longo deste artigo originou-se a partir da proposta metodológica integradora e modular do Curso Superior de Tecnologia em Design de Produto do Instituto Federal de Santa Catarina (IFSC). Este modelo de ensino busca integrar as práticas pedagógicas e as unidades curriculares em um Projeto Integrador (PI), desenvolvido pelos alunos no decorrer de cada módulo.

A partir deste contexto, o presente artigo apresenta as etapas do projeto integrador desenvolvido no Módulo 8 do referido curso, que aborda o design de embalagens e tem como escopo integrar as unidades curriculares de Design de Embalagens (Projeto de Produto), Computação Gráfica, Logística, Marketing e Tecnologia de Materiais e Processos aplicados ao Design com enfoque no desenvolvimento de embalagens. Durante a realização do projeto integrador os alunos recebem orientações dos docentes de cada uma das unidades curriculares e são agendadas apresentações periódicas das etapas desenvolvidas. Estas apresentações são efetuadas com a presença dos professores do módulo e dos demais alunos da turma para que sejam efetuadas considerações e avaliações sobre o processo e o produto desenvolvido.

Esta visão interdisciplinar que compõe o PI considera o Design de embalagens como o resultado da ação projetual em um sistema complexo, que envolve diversas competências no desenvolvimento do tema proposto. Deste modo, o projeto integrador do Módulo 8 apresentou como objetivo desenvolver ou aprimorar embalagens de um produto ou linha de produtos, a partir da análise da cooperativa e de seu contexto, propiciando a ampliação da competitividade e a diferenciação junto ao mercado. A partir destas considerações, o tema fundamentou-se na realidade e nas necessidades das cooperativas e grupos produtivos de pequeno porte, seus produtos, recursos, mercados e consumidores. 
Para o desenvolvimento deste projeto foram compostas equipes de três ou quatro alunos e foi proposto às equipes que efetuassem um mapeamento dos grupos produtivos locais e de suas principais necessidades. Com base nesta pesquisa, houve uma aproximação com o grupo produtivo selecionado para efetuar uma investigação mais aprofundada sobre a realidade vivenciada, incluindo o posicionamento da marca, a diferenciação dos produtos no mercado e a ampliação da competitividade a partir das intervenções em design.

Neste sentido, a temática proposta para o projeto integrador compreendeu " $\mathrm{O}$ Design de Embalagens como objeto de diferenciação e valorização de produtos desenvolvidos em cooperativas populares ou grupos produtivos de pequeno porte". Esta proposta baseou-se na contribuição do Design de embalagens, conjuntamente com as demais unidades curriculares do módulo, para a valorização dos produtos e o fortalecimento das cooperativas. As principais etapas que orientaram 0 desenvolvimento deste projeto foram as seguintes: i) Planejamento do Projeto de Produto; ii) Projeto Informacional e iii) Projeto Conceitual.

Os resultados pedagógicos desta proposta indicam que a integração de diferentes unidades curriculares e a aproximação dos alunos com a realidade dos grupos produtivos permitem uma melhor compreensão da complexidade do sistemaproduto. Esta categoria de trabalho acadêmico possibilita a aplicação prática dos conhecimentos, ampliando os horizontes teóricos estudados em aula, deste modo contribui para a construção das habilidades e competências necessárias para os futuros profissionais da área.

\section{PLANEJAMENTO DO PROJETO}

As cooperativas e grupos produtivos de pequeno porte presentes no mercado brasileiro vêm enfrentando diversas barreiras devido às carências e fragilidades presentes em seus produtos como, por exemplo, embalagens inadequadas ou que não valorizam seus produtos, falta de identidade, ações limitadas ou inexistentes de divulgação, dificuldades de acesso a preceitos legais e normativos e até mesmo problemas organizacionais e operacionais (MERINO, 2010).

Diante deste panorama, intervenções em Design integradas aos grupos produtivos podem contribuir para a valorização da marca e dos produtos, além de potencializar sua competitividade e diferenciação. De acordo com estes pressupostos foi iniciado o planejamento e o desenvolvimento do processo de design, partindo da análise dos grupos produtivos de pequeno porte e cooperativas existentes em Florianópolis e região metropolitana, suas principais necessidades e expectativas de parceria.

Inicialmente buscou-se um grupo produtivo parceiro, disposto a contribuir com o projeto proposto e que estivesse buscando oportunidades de melhoria para seus produtos e processos. Optou-se por trabalhar em conjunto com o Grupo Associada, visto que o mesmo atendeu aos critérios propostos e de acordo com a análise preliminar realizada pelos alunos, também apresentou uma maior necessidade de intervenções por meio do Design.

Após a seleção da cooperativa parceira, o aprofundamento do tema foi subsidiado pelos estudos realizados em campo a partir dos conceitos e ferramentas do projeto em Design e dos conceitos e ferramentas advindos do Marketing e da Logística. A imersão no contexto real da pesquisa contribuiu fortemente para a 
consolidação do projeto, pois as visitas, a observação e o levantamento de informações no local de plantio, produção, envase e armazenamento dos produtos produzidos pelo núcleo de famílias que compõem o Grupo Associada permitiram o entendimento e o mapeamento de todo sistema de produção, além do entendimento aprofundado do caráter social presente na cooperativa. Com base na organização e análise destas informações foi elaborado o planejamento do projeto, contendo as principais linhas diretivas, etapas, ferramentas e cronograma.

\section{LEVANTAMENTO DE INFORMAÇÕES}

Durante a etapa de levantamento de informações as equipes realizaram uma pesquisa bibliográfica aprofundada relativa aos produtos orgânicos, às normatizações relativas às embalagens para tais produtos, bem como sobre os órgãos responsáveis pela certificação e apoio à produção dos mesmos. Também foi realizada a pesquisa de campo por meio de observações e entrevistas com os produtores que relataram suas histórias, vivências, dificuldades e conquistas relacionadas ao desenvolvimento e aperfeiçoamento do Grupo Associada. Visando compreender todo processo de produção da cooperativa os relatos dos produtores foram registrados em gravações de áudio e fotografias durante visitas à propriedade rural, onde estes produtos são plantados, preparados, embalados e enviados para transporte.

Segundo Will (2013) o Grupo Associada é composto por seis famílias e se localiza no Vale do Rio Tijucas em Nova Trento (SC). Anteriormente à produção de orgânicos estas famílias cultivavam o fumo, porém devido aos problemas sociais e o pouco retorno financeiro para o pequeno agricultor, entre outros fatores, as famílias migraram para novas formas de cultivo da terra. A partir de então, surgiu a oportunidade de plantar frutas, legumes e verduras no sistema convencional de plantio (com agrotóxico) e vender em feiras, diretamente para o consumidor e nas escolas da região. A produção foi aumentando e, por meio de orientações e cursos ministrados pelo Serviço Brasileiro de Apoio às Micro e Pequenas Empresas (SEBRAE) as famílias decidiram envasar e produzir conservas, passando a investir em maquinário e equipamentos de cozinha.

Apesar do bom desempenho nas vendas dos produtos em questão, o grupo passou a estabelecer como meta o plantio de produtos sem agrotóxicos devido à preocupação com a saúde e o bem estar das famílias, uma vez que a produção com insumos artificiais é extremamente prejudicial para quem os maneja e também para o solo. Assim, através de incentivo do Centro de Extensão e Pesquisa Agropecuária (CEPAGRO) o Grupo Associada filiou-se à Rede Ecovida e começou a cultivar produtos orgânicos.

Esta transição vem sendo efetuada de modo gradual, pois o plantio de orgânicos requer certos cuidados com o solo e o reestabelecimento do ambiente natural. Atualmente os produtos orgânicos produzidos pelo Grupo Associada, desenvolvidos sob a marca "Raízes da Serra" são: batata inglesa, batata-doce, beterraba, cebola, cenoura, couve, repolho, repolho roxo, brócolis, alface, alho-poró, cebolinha e salsinha e também produtos transformados, como as geleias de diversos sabores e o suco de uva integral. Além da adaptação paulatina da plantação ao cultivo orgânico, outras dificuldades também necessitam ser superadas, como por exemplo, a escassez de mão de obra devido à pouca valorização do trabalho e o forte êxodo rural. 
Para que os produtores de orgânicos entrem no mercado e possam concorrer com produtos da mesma categoria, tornam-se necessários investimentos na produção e na certificação dos produtos. O selo de certificação garante a qualidade da plantação e traz segurança ao consumidor, estimulando a melhoria crescente da qualidade e a identificação dos produtos orgânicos.

\subsection{Principais dificuldades e necessidades identificadas no Grupo Associada}

Após o levantamento de informações buscou-se realizar o mapeamento das informações utilizando ferramentas advindas do Design, do Marketing e da Logística como, por exemplo, a Análise SWOT ou Análise FOFA (Forças, Oportunidades, Fraquezas e Ameaças), Análise Comparativa das estratégias utilizadas pelos concorrentes, Matriz Motivacional, Mapa do Sistema e Análise da Cadeira de Suprimentos (SCM), que auxiliaram na organização das informações e tornaram o processo de compreensão mais eficaz.

A partir da organização e análise das informações obtidas em campo verificouse que atualmente o Grupo Associada se encontra em processo de transição do cultivo de produtos convencionais para orgânicos, possuindo poucos pontos de venda, mas já buscando a fidelização de seus clientes em virtude da qualidade de seus produtos. Frente a este contexto, identifica-se que as principais necessidades e dificuldades enfrentadas pela cooperativa são relativas ao reconhecimento, inserção e posicionamento dos produtos no mercado e à dificuldade em escoar a produção, que não dispõe dos mesmos canais de distribuição oferecidos no mercado para produtos da agricultura tradicional. Além destes fatores, também existem limitações na cadeia de abastecimento atual, a qual interfere diretamente no tempo de transporte e na qualidade dos produtos.

Em relação às embalagens atuais, constata-se que embora haja uma grande preocupação com a composição e o descarte das mesmas tanto por parte dos consumidores quanto dos produtores, os produtos são geralmente acondicionados em embalagens poliméricas e de difícil separação na reciclagem, os quais conflitam pontualmente com a proposta oferecida pelos produtos orgânicos, caracterizados por advir de uma agricultura que preza pelo equilíbrio com a natureza. Dessa forma, identificou-se a necessidade da utilização de embalagens retornáveis ou recicláveis e com uma estética voltada aos produtos ecológicos (ANGEOLETTO, 2013).

Os rótulos padronizados dos orgânicos "Raízes da Serra" (Figura 1) produzidos pelo Grupo Associada são impressos em gráfica e contém apenas as informações comuns entre os produtos. Os dados que variam de um produto para outro (como por exemplo: descrição dos produtos, informações nutricionais, peso líquido, validade, instruções de consumo, ingredientes e código de barras) são impressos posteriormente na própria fábrica da cooperativa. Entretanto, o tipo de impressão utilizada faz com que as informações contidas nos rótulos se desgastem ou sejam violadas com facilidade, prejudicando a legibilidade e a confiabilidade das mesmas. 


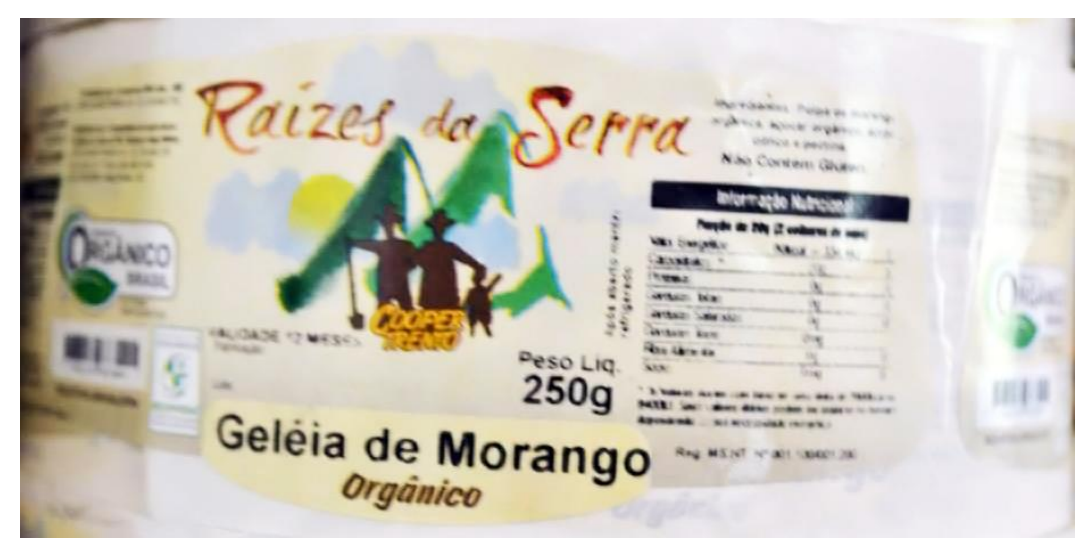

Figura 1 - Rótulo das embalagens atuais Raízes da Serra. Fonte: Grupo Associada (Foto: Elaborada pelos autores)

Embora as atividades do setor de agricultura orgânica siga um ritmo acelerado de crescimento e desenvolvimento, sua participação no mercado ainda é pequena, oferecendo poucas opções de produtos a um preço mais elevado que os convencionais (devido ao cultivo diferenciado e ao lento processo de maturação). Sendo assim, constata-se que ainda há o grande desafio de conquistar o prestígio e a confiança dos consumidores com uma produção diversificada, de qualidade e que atenda as demandas sociais de saúde, segurança alimentar e respeito ao meio ambiente (ZOLDAN, 2012).

Dessa forma têm-se o Design, em suas diversas esferas interdisciplinares, como um importante fator para a implantação de iniciativas que viabilizem a valorização, a diferenciação e o reposicionamento destes produtos no mercado, propiciando melhorias nos produtos e processos e contribuindo para o aumento da renda, bem como para o fortalecimento e consolidação dos pequenos produtores em seus locais de origem.

\subsection{0 mercado e a concorrência}

Para mapear o mercado e a concorrência foram realizadas visitas, entrevistas e observações em pontos de venda que possuíam uma maior variedade de produtos orgânicos. As informações coletadas foram organizadas em uma tabela comparativa que possibilitou a análise entre os produtos concorrentes e similares presentes no mercado, auxiliando na organização dos dados e tornando o processo de compreensão mais eficaz e embasado. Sendo assim, a análise foi realizada na região da Grande Florianópolis (SC) com o intuito de observar os principais produtos concorrentes, de forma a avaliar e identificar atributos e características relevantes, que indiquem possibilidades e oportunidades de aperfeiçoamento e de inovação para o desenvolvimento do presente projeto.

Entre os principais aspectos observados com relação às hortaliças orgânicas comercializadas notou-se o uso regular de polímeros para a fabricação das embalagens, como por exemplo: sacos plásticos, filmes de PVC (Policloreto de Vinila) e bandejas de isopor (que não possibilitam a reciclagem), além de etiquetas e rótulos que amassam e se desgastam com grande facilidade. A maioria dos produtos observados também apresenta o mesmo padrão de embalagem (geralmente sacos e filmes envoltórios ou bandejas), excesso de elementos visuais, falta de hierarquia de informações, semelhança no modo de exposição nas gôndolas, uso frequente da cor verde e de tons pastéis nas embalagens, fazendo com que os produtos não se 
diferenciem entre si e consequentemente não apresentem um diferencial estéticoformal reconhecido pelo consumidor.

Uma das únicas formas de diferenciação observadas nos pontos de venda ocorre através dos selos de certificação e da gôndola exclusiva que separa os produtos orgânicos dos convencionais. No entanto, por possuírem grandes semelhanças, as embalagens podem ser confundidas, fazendo com que alguns produtos orgânicos fiquem expostos junto aos convencionais.

Em relação aos aspectos positivos observados foi verificada uma estratégia interessante adotada por algumas empresas, que disponibilizavam divisórias de alumínio para acondicionar embalagens menores nas prateleiras, fazendo com que todas ficassem organizadas e bem apresentadas ao consumidor. Além disso, algumas das marcas concorrentes (tanto de produtos convencionais quanto de orgânicos) disponibilizavam informações a respeito da origem do produto através da impressão de um código de barras 2D (QR Code) em suas embalagens.

Como resultado das observações e análise realizadas o uso de materiais alternativos aos convencionalmente utilizados pelo setor de produtos orgânicos foi identificado como oportunidade de inovação e diferenciação. Esta oportunidade foi verificada a partir das entrevistas efetuadas com os consumidores, pois segundo os relatos obtidos as embalagens poliméricas não apresentam coerência com a proposta dos alimentos orgânicos (representados por produtos naturais, saudáveis e advindos diretamente do produtor), pois remetem para características relativas à industrialização e ao processamento de produtos.

Além deste fator constatou-se que o uso de cores e formas diferenciadas e a distribuição equilibrada e hierarquizada dos elementos gráficos e informações nas embalagens, bem como a proteção dos produtos representam algumas das possibilidades iniciais de intervenção do Design para o reposicionamento da marca, para a valorização dos produtos e para a diferenciação nos pontos de venda e .

\subsection{O consumidor de produtos orgânicos}

Com base nas observações e entrevistas qualitativas e semiestruturadas realizadas com consumidores de alimentos orgânicos foi possível identificar, avaliar e realizar um diagnóstico preliminar de seus hábitos e atitudes em relação ao modo de compra e uso destes produtos (Figura 2). Também foi possível entender as necessidades e expectativas em relação à qualidade dos produtos orgânicos e aos benefícios percebidos em comparação com os produtos da agricultura convencional. As entrevistas foram realizadas com cinco consumidores (quatro mulheres e um homem), com idade entre 30 a 60 anos que residem no município de Florianópolis e situam-se entre as classes B e C. As perguntas efetuadas abordavam as necessidades, expectativas e benefícios percebidos quanto aos alimentos orgânicos, assim como seus hábitos, atitudes e preferências, englobando o modo de compra, onde encontra os produtos e como os utiliza. 


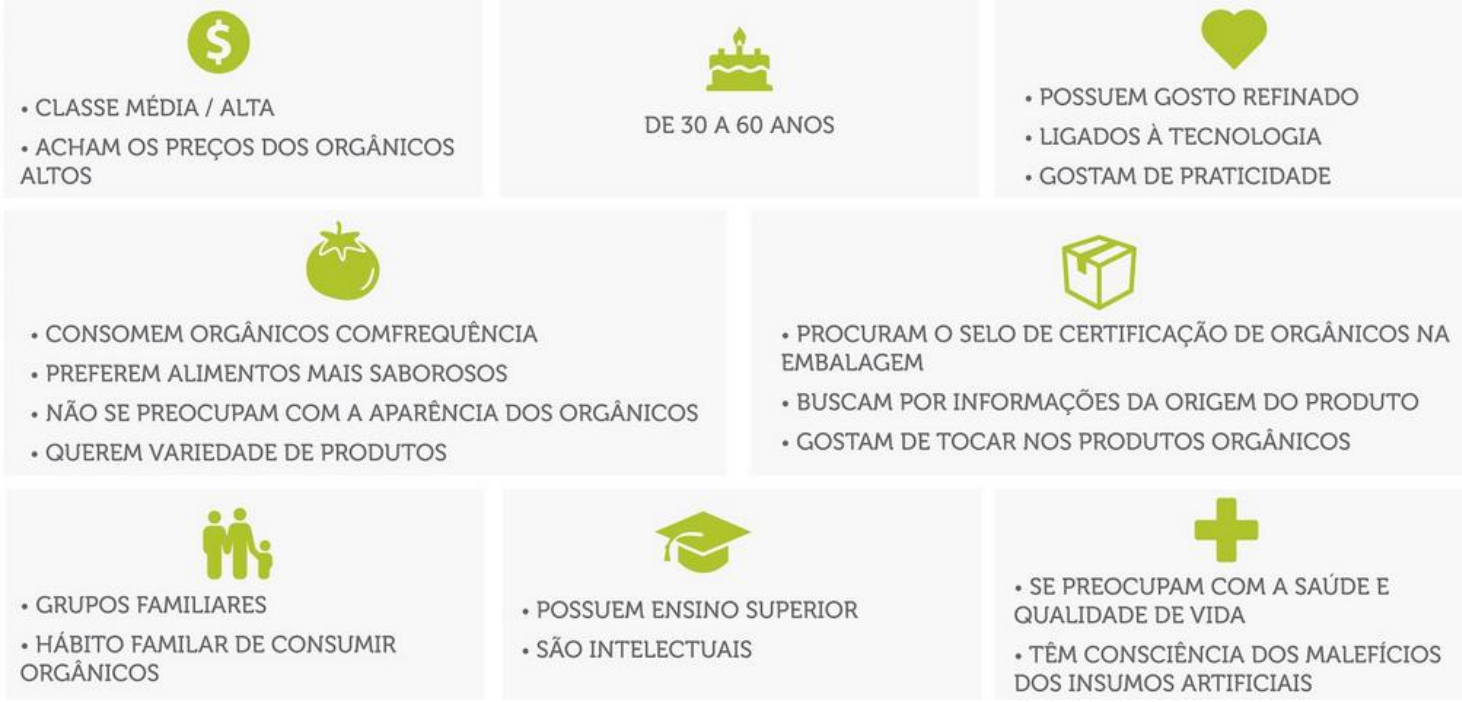

Figura 2 - Principais resultados obtidos nas entrevistas realizadas. Fonte: Elaborado pelos autores

De maneira geral, os relatos dos consumidores indicaram o hábito de alimentar-se diariamente com frutas, hortaliças e legumes orgânicos, porém poderiam consumir uma maior quantidade de produtos de maneira ainda mais frequente, caso houvesse uma maior variedade de produtos ofertados com um preço mais acessível, pois na região da Grande Florianópolis estes produtos apresentam o triplo do valor das hortaliças convencionais. Para estes consumidores, o consumo de produtos orgânicos está diretamente ligado à busca por alimentos mais saborosos, uma melhor qualidade de vida e de saúde (em longo e médio prazo). Sendo assim, os mesmos demonstraram bastante discernimento no que tange aos malefícios causados pelo uso desenfreado e indiscriminado de insumos artificiais e agrotóxicos.

Os resultados obtidos nas entrevistas permitiu a elaboração de um painel imagético (Figura 3) que contribuiu para nortear a etapa conceitual e a compreensão das principais diretrizes sob o enfoque dos consumidores. Desta forma, foram selecionadas palavras-chave e imagens que ilustrassem a rotina, as necessidades e os anseios do público-alvo, bem como o ambiente em que estes produtos estão inseridos para o consumo. Estas representações buscaram compor um retrato dos hábitos do consumidor, com o intuito de refletir constantemente sobre o perfil humano para o qual o produto se destinará (MESTRINER, 2001), servindo assim, como forma de inspiração para desenvolvimento de proposições no decorrer do projeto.

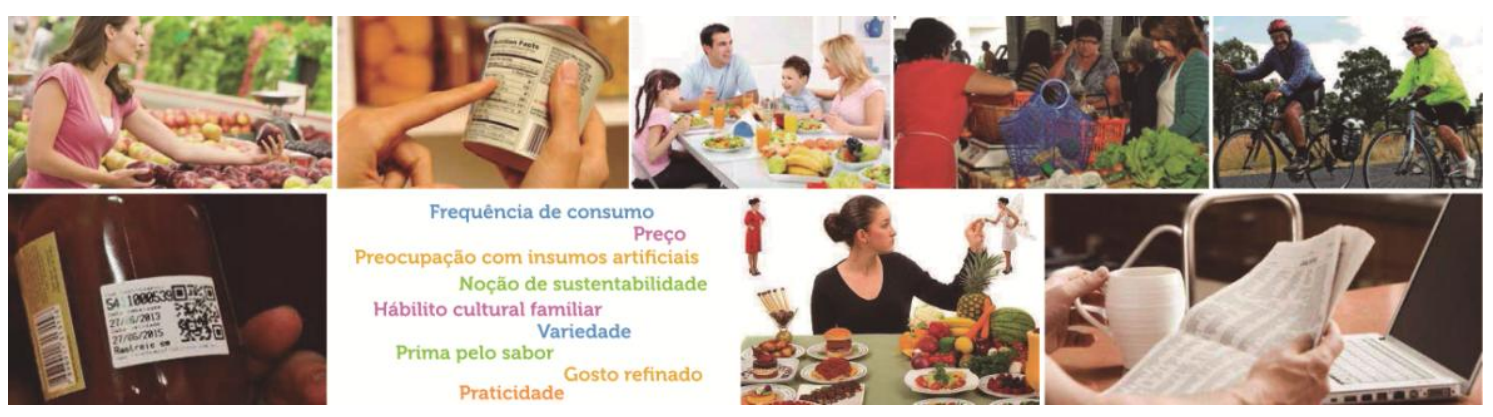

Figura 3 - Painel imagético.

Fonte: Elaborado pelos autores 
Com base no resultado das pesquisas realizadas foram definidos os seguintes requisitos de projeto para as embalagens: fornecer informações sobre o produto e os produtores; proteger os produtos; melhorar a rastreabilidade dos produtos; atrair a atenção do consumidor; ser condizente com a proposta de produtos orgânicos; ter identidade visual condizente com o grupo de produtores e entre as embalagens da linha; apresentar baixo custo e permitir o contato do cliente com o produto.

\section{PROJETO CONCEITUAL}

$\mathrm{Na}$ etapa conceitual foram considerados o contexto do projeto, as ideias preliminares sobre a configuração do produto como um todo, bem como a geração e a seleção de alternativas. Portanto, nesta etapa as reuniões foram realizadas com mais frequência, a fim de tornar o processo mais interativo, colaborativo e para que os resultados obtidos contemplassem as proposições estabelecidas para os produtos e processos. Para o desenvolvimento de cenários e alternativas os requisitos mais relevantes foram elencados e agrupados com a finalidade de desenvolver conceitos diferenciados, que posteriormente foram aprimorados e combinados entre si. Os esboços e renderings gerados durante toda a etapa de conceituação foram reunidos em um caderno de criação, o qual foi organizado de acordo com a ordem de desenvolvimento.

As alternativas desenvolvidas para as embalagens foram testadas com os produtos de forma a validar sua eficácia, descartando as que não cumpriam a proposta. Nesta etapa também foi aprimorada a identidade visual da marca "Raízes da Serra", para qual foram levados em conta conceitos como: proposta gráfica condizente com a identidade e com a proposta do grupo; o meio rural e a proximidade com a natureza e a família, o cooperativismo e as ferramentas de trabalho. Estas modificações resultaram na simplificação dos elementos visuais para transmitir a ideia de um produto natural, simples e confiável por meio dos elementos visuais.

Algumas das técnicas utilizadas no processo de criação, como o agrupamento de requisitos e a elaboração de cadernos de criação, consistem em ferramentas que tem sido desenvolvidas e aprimoradas pelos alunos ao longo do curso e principalmente durante o desenvolvimento de outros projetos integradores. Outra preocupação da equipe de projeto foi o entendimento claro dos processos existentes no Grupo Associada. A organização, visualização e melhoria dos fluxos e processos existentes no sistema foram efetuadas a partir da ferramenta System Map ou Mapa do Sistema (Figura 4), que faz parte dos procedimentos para o design de sistemas produto e serviços (VAN HALEN et al, 2005). 


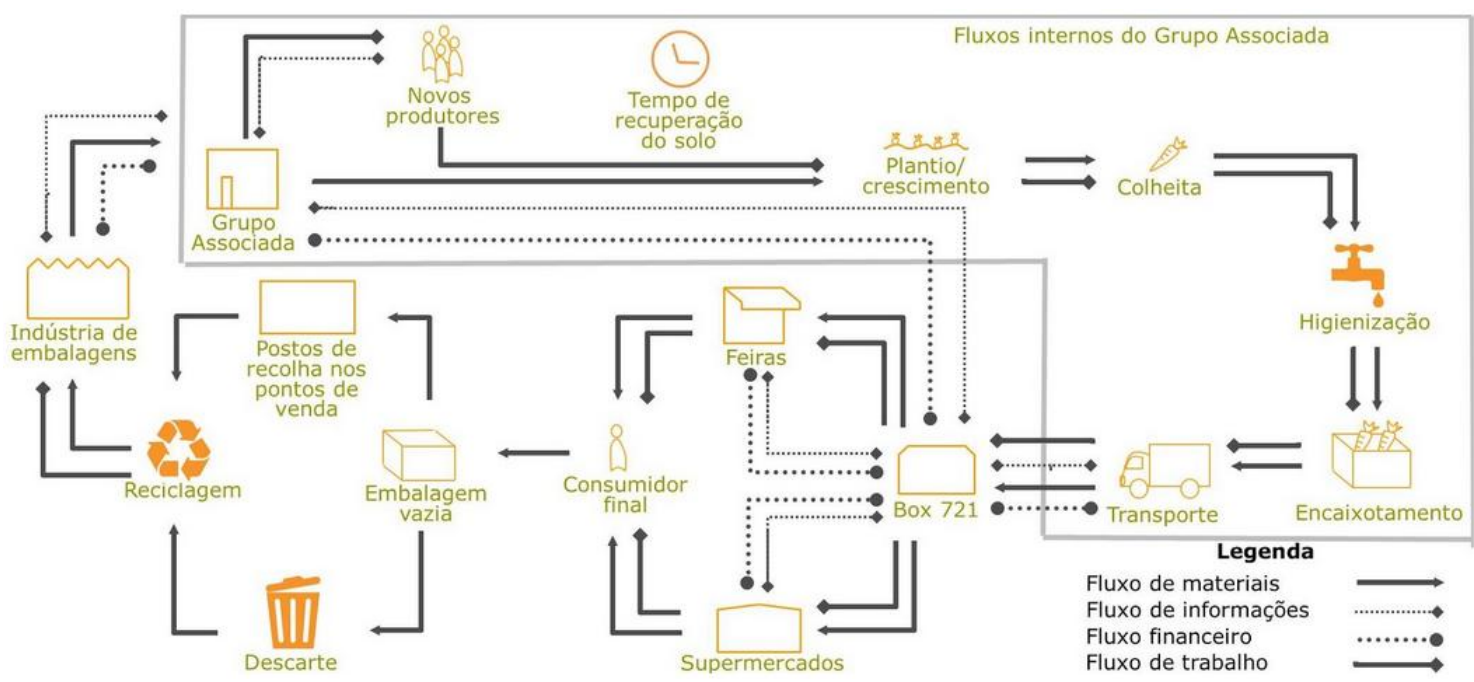

Figura 4 - Mapa do sistema do Grupo Associada.

Fonte: Elaborado pelos autores

Este procedimento permitiu a visualização dos fluxos de materiais, financeiro, de informações e de trabalho com a finalidade de compreender o sistema existente. Partindo destes dados foi efetuado um mapeamento detalhado do fluxo produtivo, incluindo análise de fornecedores, estoque, localização, transporte, distribuição e informação. Deste modo foi possível identificar as lacunas e possíveis melhorias para aperfeiçoar a cadeia de abastecimento e distribuição do referido grupo. As principais proposições concentram-se principalmente no estabelecimento de novas parcerias com fornecedores e distribuidores, de modo a ampliar a produção e atender o aumento da demanda. Também foram efetuadas proposições referentes ao sistema de gerenciamento de produtos, processos e informações visando a manutenção da qualidade e o fornecimento continuado dos produtos para consolidar a confiança dos consumidores e fortalecer a imagem da marca.

\section{PROPOSIÇÕES EM DESIGN INTEGRADAS AO MARKETING E À LOGÍSTICA}

As proposições relativas ao Design de embalagens foram selecionadas e categorizadas em uma tabela comparativa de acordo com os alimentos que a embalagem deveria acondicionar e os requisitos de projeto. Deste modo, para a seleção das alternativas finais foram escolhidas as embalagens que melhor atendiam aos requisitos e comportavam os alimentos especificados (Figura 5). 


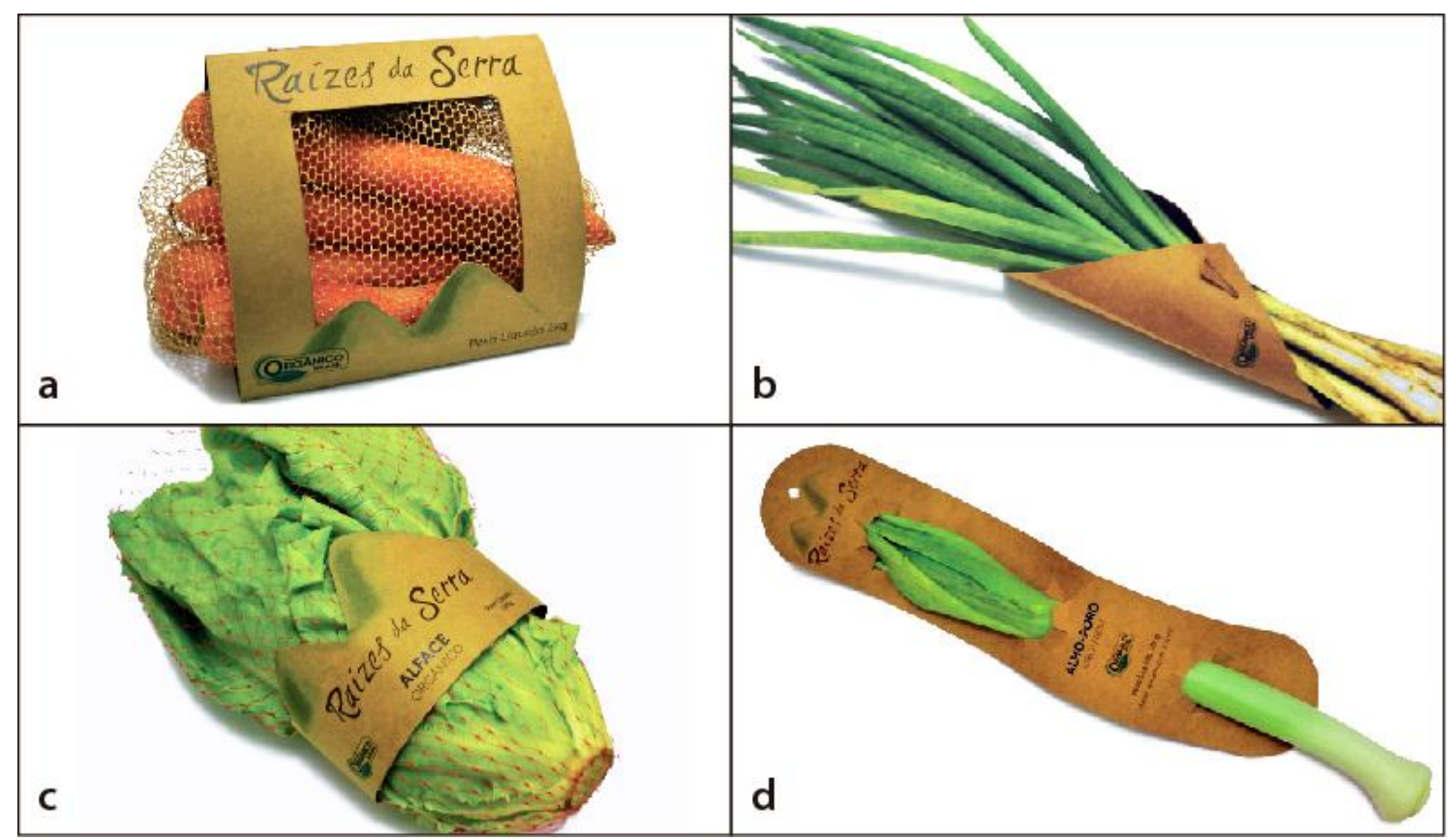

Figura 5 - Embalagens para hortaliças orgânicas: a) Batata inglesa, batata doce, beterraba, cebola, cenoura, couve, repolho, repolho roxo, brócolis; b) Cebolinha e salsinha; c) Alface; d) Alho-poró. Fonte: Elaborado pelos autores

Os materiais recomendados para a confecção das embalagens são o papel kraft pardo de gramatura $300 \mathrm{~g} / \mathrm{m}^{2}$ devido à sua resistência mecânica, sendo indicado para embalagens de alimentos. Propõe-se também o uso da rede plástica (conhecida como "redinha") intensivamente utilizada para embalar frutas e legumes por apresentar resistência, não danificar o produto e ser adaptável ao acondicionamento dos diferentes produtos. Esta rede é produzida em polietileno flexível, sendo durável, reciclável, de fácil manuseio e de baixo custo. Suas tramas permitem que os vegetais e frutas tenham contato com o oxigênio permanecendo frescos por mais tempo e também proporciona ao cliente o contato tátil e visual com o produto.

Nesta etapa do projeto as unidades curriculares de Computação Gráfica, e Tecnologia de Materiais e Processos foram de fundamental importância para o desenvolvimento dos produtos. Os processos propostos para a produção das embalagens são a impressão offset e a laminação do papel, com o objetivo de ampliar a resistência à umidade, visto que os legumes deverão ser embalados logo após a higienização para que o papel não rasgue ou se torne frágil e a tinta da impressão não se apague ou borre. As embalagens propostas buscam destacar não apenas a marca, mas as informações necessárias ao consumidor. Nesta etapa também foram realizados estudos das planificações e validações ergonômicas, que fundamentaram a busca por soluções simples, funcionais e adequadas.

As principais funcionalidades requeridas no projeto de embalagens foram: conter os produtos e facilitar a identificação durante o transporte, estocagem e exposição, evitando que os produtos orgânicos se misturem com produtos não orgânicos ou com produtos de outros fabricantes. Neste sentido, as embalagens consistem em elementos-chave para informar o consumidor sobre o conteúdo, quantidade e composição do produto e também fornecer instruções e informações de uso, selo de certificação de orgânicos, rastreabilidade e reciclagem, entre outros. 
O destaque da embalagem no ponto de venda possibilita uma percepção diferenciada do consumidor a respeito do produto, fator que em muitos casos é determinante na aquisição do produto pelo cliente final. Tendo em vista a ampliação da cadeia de distribuição, o fortalecimento da marca e uma maior aproximação com o consumidor propõe-se que a nova embalagem contenha identificação QR Code para que o consumidor possa rastrear a origem de seu produto através do site do Grupo Associada. O desenvolvimento de um site permite a ampliação dos canais de contato com e atendimento ao cliente, podendo fornecer informações, dicas e receitas, além de transmitir a história e a filosofia da empresa.

Com base na análise do contexto do Grupo Associada e do delineamento do plano de marketing também verificou-se a importância do reposicionamento das embalagens no mercado. Para atender a esta proposta foram desenvolvidos expositores específicos para os produtos "Raízes da Serra" baseados no redesign da marca, com a finalidade de organizar e expor os produtos nos pontos de venda. Neste caso propõe-se o estabelecimento de parcerias colaborativas entre os produtores e distribuidores, visando propiciar uma boa localização do expositor para ampliar a visibilidade do produto. $O$ expositor tem como objetivo atrair a atenção do consumidor para os produtos e para a marca, assim como garantir a organização nos pontos de venda (Figura 6). Os principais materiais propostos para a confecção do expositor são: madeira (utilizada com o propósito de remeter à natureza e trazer resistência à estrutura); aço inoxidável (presente na parte do expositor destinada às embalagens suspensas, visando ampliar a resistência e não oxidar com a umidade dos alimentos); acrílico (material rígido e durável utilizado para composição das divisórias nas prateleiras, mantendo os produtos organizados e permitindo uma boa visibilidade dos mesmos).
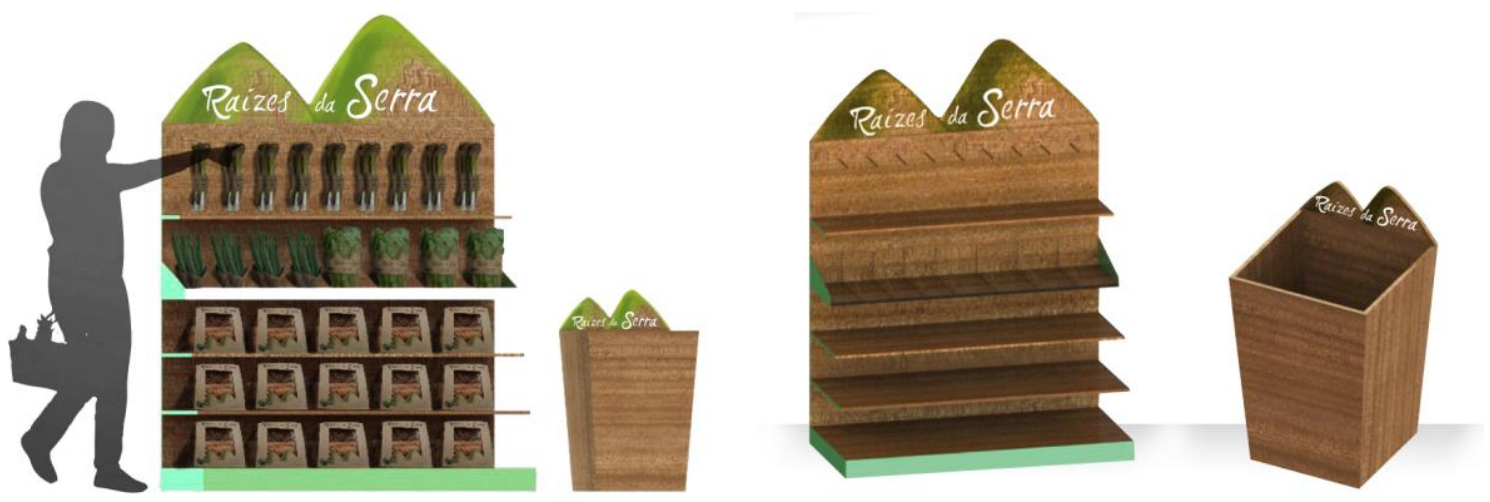

Figura 6 - Caixa coletora e expositor. Fonte: Elaborado pelos autores

A partir da análise dos principais fluxos da cadeia produtiva e da entrevista com os consumidores também identificou-se a necessidade de desenvolver caixas coletoras a serem dispostas nos pontos de venda visando o descarte adequado das embalagens. Esta ação inicial permite a associação de novos procedimentos que integrem produtores, distribuidores e usuários para viabilizar a coleta e a restituição dos resíduos sólidos para reaproveitamento, dando início ao processo de logística reversa. Desta forma, todas as embalagens "Raízes da Serra" deverão apresentar um texto informativo orientando o consumidor a realizar o descarte adequado em pontos de 
vendas específicos, para que as mesmas sejam reutilizadas ou encaminhadas para a reciclagem visando produzir novas embalagens.

\section{CONSIDERAÇÕES FINAIS}

O processo de desenvolvimento de uma linha de embalagens para hortaliças orgânicas cultivadas pela cooperativa Grupo Associada visando a integração das disciplinas do módulo de Design de Embalagem esteve desde sua pré-concepção, integrado à realidade social, econômica e produtiva do grupo em questão, o qual resultou na definição de proposições em design baseadas na simplicidade, nos elementos da natureza e na artesanalidade.

A empatia com o tema foi se tornando cada vez mais acentuada e evidente no decorrer do processo, pois os estudantes estavam respaldados pelo levantamento de informações detalhado e criterioso realizado na primeira etapa do projeto. A inserção dos discentes no contexto real permitiu que a etapa de desenvolvimento de conceitos para os produtos e processos fosse motivadora e empolgante, embora tenha exigido grande dedicação e esforço para que se chegasse a uma proposta adequada para a cooperativa.

A partir da análise do contexto que incluiu o levantamento da realidade vivenciada pela cooperativa sob a ótica do Design, do Marketing e da Logística, foram desenvolvidos o plano de marketing e a análise da cadeia de abastecimento e distribuição, que propiciaram subsídios para o desenvolvimento de melhorias para os produtos e processos, incluindo o desenvolvimento de uma linha de embalagens para hortaliças, o redesign da marca e desenvolvimento de uma identidade visual que valorizasse o conteúdo e as embalagens, ponto importante observado pelos estudantes para a valorização dos produtos.

O reposicionamento e o destaque dos produtos no ponto de venda foram considerados aspectos fundamentais para o fortalecimento da marca da cooperativa e para o reposicionamento das embalagens. O estabelecimento de ações iniciais e acordos setoriais para articulação dos processos de logística reversa também fortalece a proposta da marca, pois contribui para ampliar a conscientização dos consumidores e incluí-los na minimização dos impactos gerados pelo descarte, facilitando o recolhimento dos resíduos sólidos para reuso ou reciclagem.

Com base nos resultados obtidos observou-se que a abordagem interdisciplinar das unidades curriculares do módulo de Design de Embalagens associada ao processo integrado de projeto propiciou aos alunos uma maior aproximação com a realidade e a aplicação prática dos estudos realizados em aula. A associação de técnicas e ferramentas oriundas das diferentes áreas do conhecimento permitiu uma compreensão ampliada do sistema-produto e a compreensão do design como parte dos processos mais amplos que envolvem o ciclo de vida do produto (desde a extração da matéria-prima até o descarte final). A realização de um projeto integrador amplia também a compreensão dos consumidores, dos setores produtivos e distributivos e do posicionamento da empresa frente a estes fatores. Este processo didático-pedagógico baseado na integração de conhecimentos auxiliou a aproximação dos discentes com a problemática existente em contextos reais e permitiu o desenvolvimento de intervenções em design mais adequadas à realidade da cooperativa e de seus associados. 
REFERÊNCIAS

ANGEOLETTO, Fernando. Assessor de Comunicação. Entrevista concedida no CEPAGRO em Florianópolis - SC, 02 Set. 2013.

MERINO, Giselle Schmidt Díaz et al. Estratégia de valorização para pequenos grupos produtivos com base na identidade. In: CONGRESSO BRASILEIRO DE PESQUISA E DESENVOLVIMENTO EM DESIGN, 9, 2010, São Paulo. Anais... Disponível em:<http://blogs .anhembi.br/congressodesign/anais/artigos/69732.pdf>. Acesso em: 02 set. 2013.

MESTRINER, Fabio. Design de Embalagem - Curso Básico. São Paulo, Makron Books, 2001.

WILL, Antônio. Membro do Grupo Associada. Entrevista concedida na Coopertrento em Nova Trento - SC, 21. Set. 2013.

ZOLDAN, Paulo Cesar; MIOR, Luiz Carlos. Produção orgânica na agricultura familiar de Santa Catarina. EPAGRI: Florianópolis, 2012. Disponível em: <http://www.epagri.sc.go v.br/files/agric_organica.pdf>. Acesso em: 22 set. 2013.

VAN HALEN, C.; VEZZOLI, C.; WIMMER, R. Methodology for product service system innovation. How to implement clean, clever and competitive strategies in European industries. Royal Van Gorcum. Assen: 2005. 